\title{
Multivariate analysis of clinicopathological and prognostic significance of miRNA 106b 25 cluster in gastric cancer
}

Fangxuan $\mathrm{Li}^{1,2+}$, Jinchao Huang ${ }^{2,3+}$, Juntian $\mathrm{Liu}^{2^{*}} \mathbb{0}$, Wengui $\mathrm{Xu}^{3^{*}}$ and Zhiyong Yuan ${ }^{1^{*}}$

\begin{abstract}
Background: miRNA 106b 25 cluster were demonstrated to be an oncogene. In previous study, we had analyzed the diagnostic significance of miRNA 106b 25 based on its carcinogenesis effect. The significance of miRNA 106b 25 for prognosis of gastric cancer were not researched.

Methods: We applied multivariate analysis of PCA, PLS-DA and Cox Regression for clinicopathological features and survival time to explore the significance of miRNA 106b 25 expression in plasma and cancer tissues for gastric cancer.

Results: The expression of miRNA 106b, miRNA 93 and miRNA 25 in plasma were positively correlated with their expression in tumor tissues. Via PCA analysis, it was found that miRNA 106b 25 expression in plasma and tumor, T, $\mathrm{N}$ and TNM stage were correlated with each other. Via PLS-DA analysis, we identified that T, N and TNM stage were important factors for miRNA 106b 25 expression both in plasma and tumor (all VIP value > 1.2). According to loading weights of variables for the first and second components, it was found that the importance of the miRNA 106b 25s expression carried with the progressed stage of gastric cancer. In the survival analysis, COX regression showed that T stage, plasma miRNA 106b and tumor miRNA 93 were significant risk factors for overall survival [HR: 0.400 (0.205$0.780) ; P=0.007 ; \mathrm{HR}: 0.371(0.142-0.969), P=0.043 ; 0.295$ (0.134-0.650), $P=0.002]$.
\end{abstract}

Conclusion: Plasma and tumor miRNA 106b 25 expression correlated with T, N and TNM stage. Increased miRNA 106b 25 expression was important characters carried with gastric cancer progression. T stage, plasma miRNA106b and tumor miRNA 93 significant risk factors for overall survival.

Keywords: miRNA 106b, miRNA 93, miRNA 25, Gastric cancer, PCA, PLS-DA

\section{Background}

miRNA 106b 25 cluster were demonstrated to be an oncogene, which promote malignant cell proliferation, migration, invasion as well as tumor angiogenesis $[1$,

\footnotetext{
*Correspondence: ljt641024@126.com; webguixy@163.com; zyuan@tmu.edu.cn

${ }^{\dagger}$ Fangxuan Li and Jinchao Huang contributed equally to this work ${ }^{1}$ Department of Radiotherapy, Tianjin Medical University Cancer Institute and Hospital, National Clinical Research Center for Cancer, Tianjin's Clinical Research Center for Cancer, Key Laboratory of Cancer Prevention and Therapy, Huanhuxi Road, Hexi District, Tianjin 300060, China ${ }^{2}$ Department of Cancer Prevention, Tianjin Medical University Cancer Institute and Hospital, Huanhuxi Road, Hexi District, Tianjin 300060, China ${ }^{3}$ Department of Molecular Imaging and Nuclear Medicine, Tianjin Medical University Cancer Institute and Hospital, Huanhuxi Road, Hexi District, Tianjin 300060, China
}

15]. The miRNA 106b 25 polycistronic contain three pre-miRNAs including highly conserved miRNA 106b, miRNA 93 and miRNA 25 [9]. These three miRNAs are targeted in the intron 13 of 515 -bp region of chromosome $7 \mathrm{q} 22$ for gene MCM7 and present active transcription in the MCM7 primary RNA transcription [6, 15]. This cluster has been reported to be over-expressed in many cancers, such as esophageal cancer [21], prostate cancer [7, 16], non-small cell lung cancer [17], and hepatic cell cancer [20]. The trigger targets of their oncogenic process involving E2F1 and TGF- $\beta$, as well as Retinoblastoma protein (RB) gene, tumor protein 53 (TP53) [23] and phosphatase and tension homolog deleted on chromosome (PTEN) have been demonstrated in regulating mechanism of miRNA 106b 25 [24].

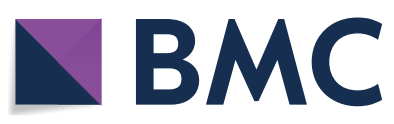

C The Author(s) 2019. This article is distributed under the terms of the Creative Commons Attribution 4.0 International License (http://creativecommons.org/licenses/by/4.0/), which permits unrestricted use, distribution, and reproduction in any medium, provided you give appropriate credit to the original author(s) and the source, provide a link to the Creative Commons license, and indicate if changes were made. The Creative Commons Public Domain Dedication waiver (http://creativecommons.org/ publicdomain/zero/1.0/) applies to the data made available in this article, unless otherwise stated. 
In previous study, the miRNA 106b 25 cluster implement proliferative, anti-apoptotic, cell cycle-promoting proficiency in cell experiments and tumorigenicity in vivo $[4,22]$. Petrocca's study suggests that cancer cells can alternate action mechanisms of miRNA 106b 25 to facilitating cells regeneration and relieving apoptosis [14]. miRNA 106b 25 over-expression increased apoptosis through regulation of the tumor suppressor genes [8]. Furthermore, suppression of miRNA 25, 93 and $106 \mathrm{~b}$ results in facilitation of G1/S phase transition and decreasing cell cycle G0/G1 phase arrest [8]. Many studies demonstrated that the miRNA 93 also play an important role in enabling angiogenesis in caner [3].

Gastric cancer is the fourth most common cancer and the second leading cause of cancer related death in the world wide [18]. It had demonstrated that miRNA 106b and miRNA 93 were upregulated in primary tumors and highly expressed in all gastric cancer cell lines $[5,10]$. miRNA 106b 25 clusters may take part in tumorigenesis, progression of gastric cancer via negative regulate E2F1, TGF- $\beta$ pathway $[4,9,10,14]$. Tumor suppressing gene $\mathrm{RB}$ and PTEN and oncogene P21 and Bim [8] also were the direct targets of miRNA 106b 25. So, many studies suggested that the miRNA 106b 25 may be an intrinsic factor of gastric carcinogenesis. In large-scale analysis, the plasma concentrations of miRNA 106b were significantly higher in gastric cancer patients, and significantly decreased in pre-operative serum compared with postoperative serum [13]. In TCGA database, all these three miRNAs were significantly higher expressed in cancer when comparing with normal tissues (Additional file 1: Table S1).

In our vitro study, inhibiting miRNA $106 \mathrm{~b} \sim 25$ cluster via transfecting antisense RNA can influence proliferation, migration, and invasion, G0G1 phase arrest of gastric cancer cells [26]. In clinic, we found that three components of miRNA 106b 25 cluster expressed consistently at a high level both in tumor specimens and plasma, and associated with clinical pathological factors [27]. When comparing the diagnostic efficacy, plasma miRNA 106b was significantly higher diagnostic efficacy than CA724, CA242 and CA199 [2], the diagnostic efficacies of miRNA 93 and miRNA 25 were significantly higher than CA199 [11]. However, the significance of miRNA 106b 25 for prognosis of gastric cancer were not researched. As well as in TCGA data base (Additional file 1: Table S1), the survival significance was not observed due to many studies lacking survival data. In this study, we examined 60 gastric patients' miRNA 106b 25 expression level in plasma and cancer tissues. Then analyzed the association between miRNA 106b 25 expression and clinicopathological features and overall survival of gastric cancer patients after 5-years following-up.

\section{Methods \\ Patients}

We collected 60 gastric cancer tissues samples from March to May in 2013 at Tianjin Medical University Cancer Institute and Hospital, each one paired with non-tumor gastric tissue(at least $5 \mathrm{~cm}$ away from the edge of tumor, and there was no tumor cell confirmed by a pathologist $[25,30]$ ) and perioperative peripheral blood sample from the same patient. Inclusive criteria were: (1) gastric cancer patients received radical resection for stomach tumor. (2) all histological diagnosis was confirmed as gastric adenocarcinoma. All clinical data were analyzed according to the 8th stomach cancer tumor-node-metastasis (TNM) staging classification of the Union of International Control Cancer (UICC) [28]. (3) all patients had not received chemotherapy or radiotherapy before collecting samples. (4) all patients had not chronic disease or infectious diseases or history of other malignancy.

Informed consent was taken from every subject, and the Human Research Ethics Committee of Tianjin Medical University approved all aspects of this study.

\section{Samples}

All tissues samples were preserved in liquid nitrogen after removal from human body. Blood samples were obtained immediately following diagnosis and prior to any oncological treatment. The peripheral blood $(5 \mathrm{~mL})$ samples were collected into ethylenediaminetetraacetic acid (EDTA) anticoagulative tubes immediately. After collection, the blood samples were subjected for isolation of cell-free nucleic acids by using a three-spin protocol ( $2000 \mathrm{~g}$ for $30 \mathrm{~min}, 4000 \mathrm{~g}$ for $5 \mathrm{~min}, 8000 \mathrm{~g}$ for $5 \mathrm{~min}$ ) to prevent contamination from cellular nucleic acids.

\section{RNA extraction and detection of miRNAs}

Total RNA of tissues was extracted by using Trizol (Invitrogen, USA); Plasma RNA was extracted by using acid phenol according to the manufacturer's instructions. Total RNA was quantified by microfluidics analysis (Gene Quant, Switzerland). The amounts of miRNAs were quantified in duplicate by quantitative reverse transcription polymerase chain reaction (RT-PCR) using the human TaqMan MicroRNA Assay Kits (Applied Biosystems, Foster City, CA, USA). After the reverse transcription reaction which was carried out with TaqMan MicroRNA Reverse Transcription Kit (Applied Biosystems), cDNA solution was amplified using TaqMan Universal PCR Master MixII with no Amp Erase UNG (Applied Biosystems). RT-PCR was run on 7500 Real 
Time PCR system (Applied Biosystems), and the cycle threshold $(\mathrm{Ct})$ values were calculated with the SDS 1.4 software (Applied Biosystems). All reactions were performed in triplicate.

Through the $2^{-\Delta \Delta \mathrm{Ct}}$ method, expressions of miRNAs by U6, while the expressions of miRNAs from tissues samples were normalized by miRNA 39 according to the manufacturer's instructions. The $\mathrm{Ct}$ was calculated by subtracting the $\mathrm{Ct}$ values of reference substance from the $\mathrm{Ct}$ values of the interesting miRNAs. Mean $\mathrm{Ct}$ and standard deviation values were calculated without outliers (i.e., replicates with $\mathrm{Ct}$ differing by more than one cycle from the median). The $\Delta \Delta \mathrm{Ct}$ was then calculated by subtracting $\Delta \mathrm{Ct}$ of the median of control samples from $\Delta \mathrm{Ct}$ of study group. Fold change was calculated by the equation $2^{-\Delta \Delta \mathrm{Ct}}$ [24]. Then, we used division calculation to achieve the $2^{-\Delta \Delta \mathrm{Ct}}$ multiple between gastric cancer tissues and one to one correspondence adjacent nontumorous tissues.

\section{Statistical methods}

Statistical analyses were performed using the SPSS software package (version 16.0; SPSS, Chicago, IL, USA). Two-tailed $P$-values of less than 0.05 were considered to statistically significant difference. Continuous variable was described by median and mean \pm standard deviation $(\bar{x} \pm \mathrm{s})$. Independent sample $t$ test was used in comparison of continuous variables. The Chi squared and Fisher exact tests were applied in categorical variable for univariate analysis.

All clinical features were set as variable $\mathrm{X}$ to establish the matrix. Then SIMCA-P 13.0 (Umea, Sweden) was applied in matrix analysis. Principal component analysis

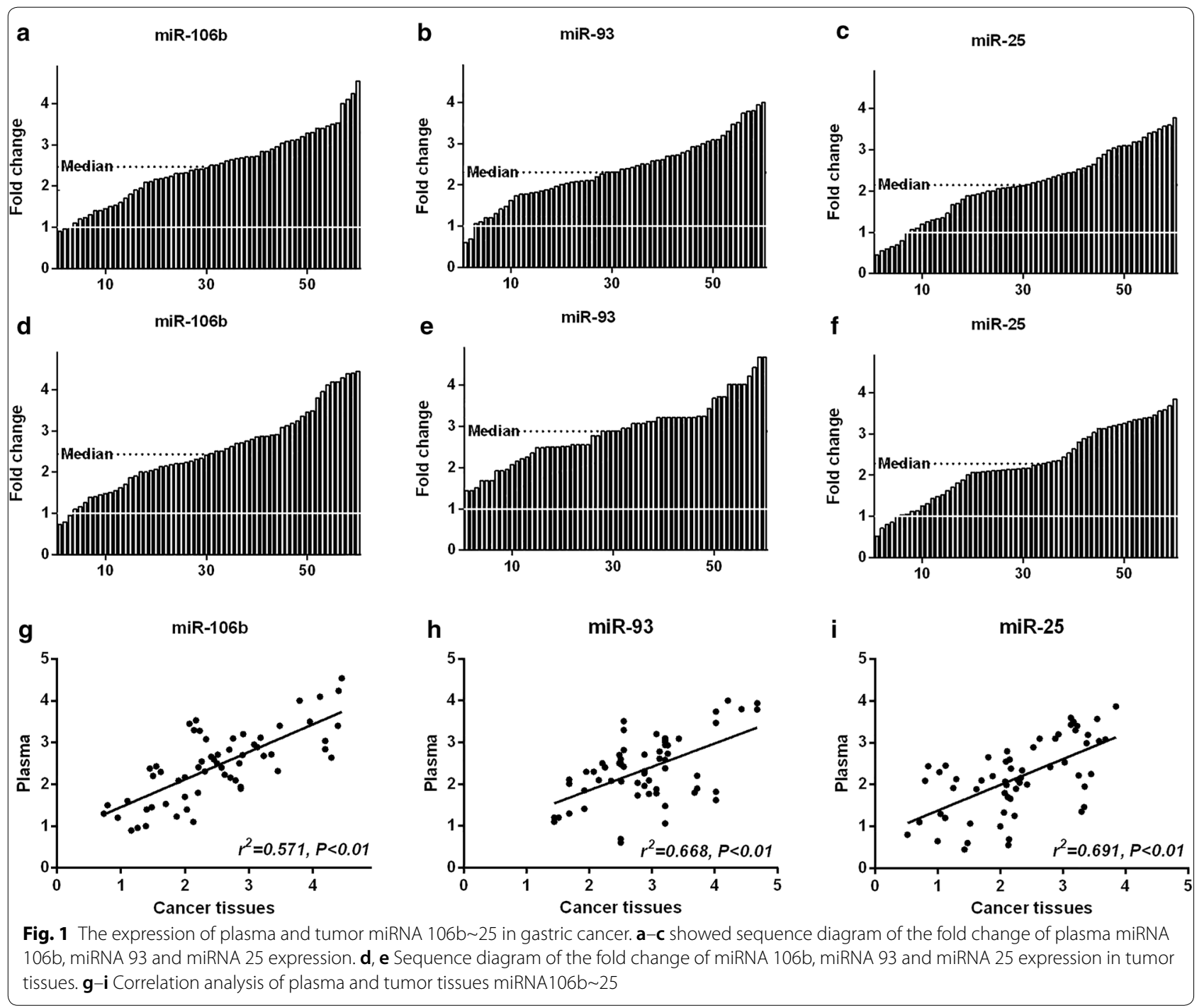


Table 1 The summary of clinicopathological features and miRNA106b 25 of gastric cancer patients

\begin{tabular}{ll}
\hline Clinicopathological features & \\
\hline Age (mean \pm SD, year) & $53.75 \pm 9.76$ \\
Sex (male/female) & $53 / 7$ \\
Location (proximal/middle/distal) & $16 / 12 / 32$ \\
Tumor size (<5 cm, $\geq 5 \mathrm{~cm})$ & $26 / 34$ \\
Bormann type (I/II/III/IV) & $5 / 14 / 31 / 10$ \\
T stage (T1/T2/T3/T4) & $3 / 13 / 4 / 40$ \\
$\mathrm{~N}$ stage (N0/N1/N2/N3) & $19 / 18 / 9 / 14$ \\
TNM stage (I/II/II/IV) & $12 / 12 / 31 / 5$ \\
Histological grade (well/poor differentiated) & $17 / 43$ \\
Plasma miRNA 106b (median, range) & $2.465(0.90-4.54)$ \\
Plasma miRNA 93 (median, range) & $2.305(0.60-4.00)$ \\
Plasma miRNA 25 (median, range) & $2.145(0.45-3.87)$ \\
Tumor miRNA 106b (median, range) & $2.430(0.73-4.45)$ \\
Tumor miRNA 93 (median, range) & $2.880(1.44-4.68)$ \\
Tumor miRNA 25 (median, range) & $2.165(0.52-3.85)$ \\
\hline
\end{tabular}

(PCA) was used for profile analysis; meanwhile, partial least-squares discriminant analysis (PLS-DA) was used to confirm the significant variable for the categories.
Loading plot and Variable Importance for the Projection (VIP) was used to determine the significant important variable for the miRNA 106b 25 (VIP> 1.2) [7].

\section{Results}

Expression of miRNA106b 25 in plasma and cancer tissues in gastric cancer

Figure 1a-c showed sequence diagram of the fold change of plasma miRNA 106b, miRNA 93 and miRNA 25 , which set the fold change of "1" as cutting line. The median fold change of plasma miRNA 106b, miRNA 93 and miRNA 25 were $2.465,2.305$ and 2.145 , respectively, the mean fold change of plasma miRNA 106b, miRNA 93 and miRNA 25 were $2.457 \pm 0.856,2.3512 \pm 0.796$, $2.162 \pm 0.846$ (Table 1 ).

Then, we determined the levels of miRNA 106b, miRNA 25 and miRNA 93 relative to the paired normal tissues. Figure $1 \mathrm{~d}-\mathrm{f}$ showed sequence diagram of the fold change relative to adjacent non-tumorous tissues. The median fold change of tumor miRNA 106b, miRNA 93 and miRNA 25 were $2.430,2.880,2.165$, respectively, which was significantly increased expression. The mean fold change of tumor miRNA 106b, miRNA
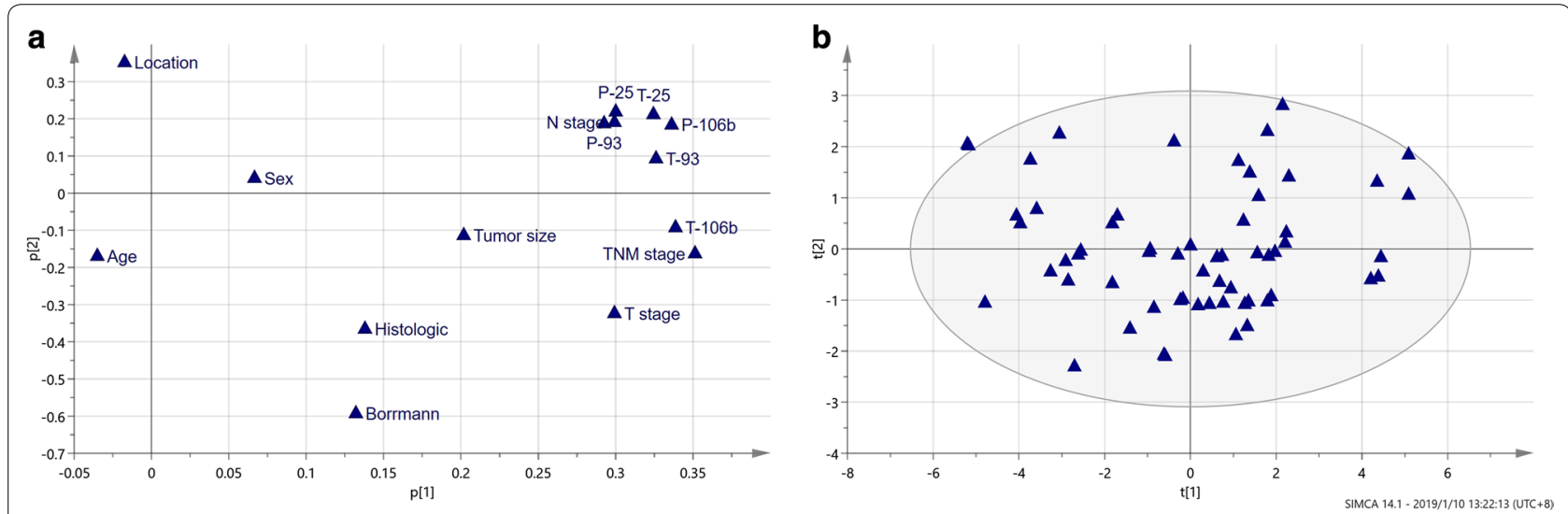

C

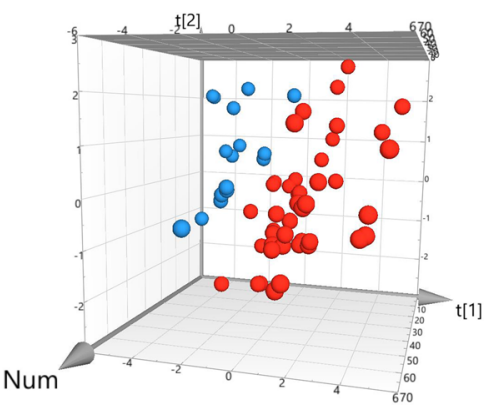

d

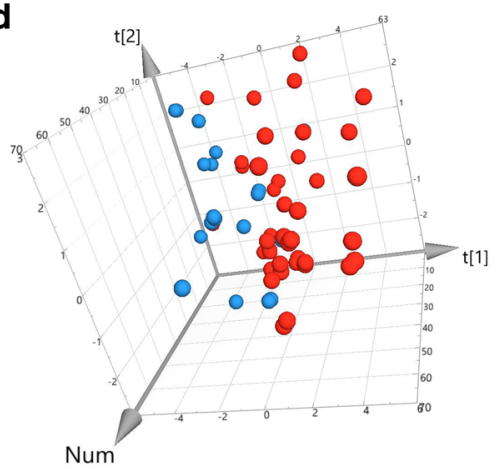

e $t[2]$

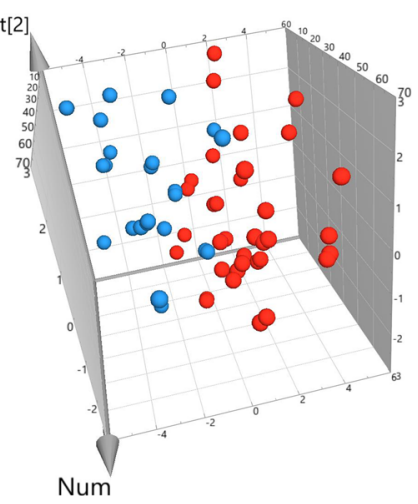

Fig. 2 PCA analysis for clinicopathological features and miRNA 106b 25 in gastric cancer. a, b Loading plot and score scatter in PCA analysis. c-e 3D score plot according to T stage, N stage, TNM stage in PCA, Blue: T1 + T2, NO, TNM I+ II stage, respectively; Red: T3 + T4, N1-N3, III + IV stage, respectively 

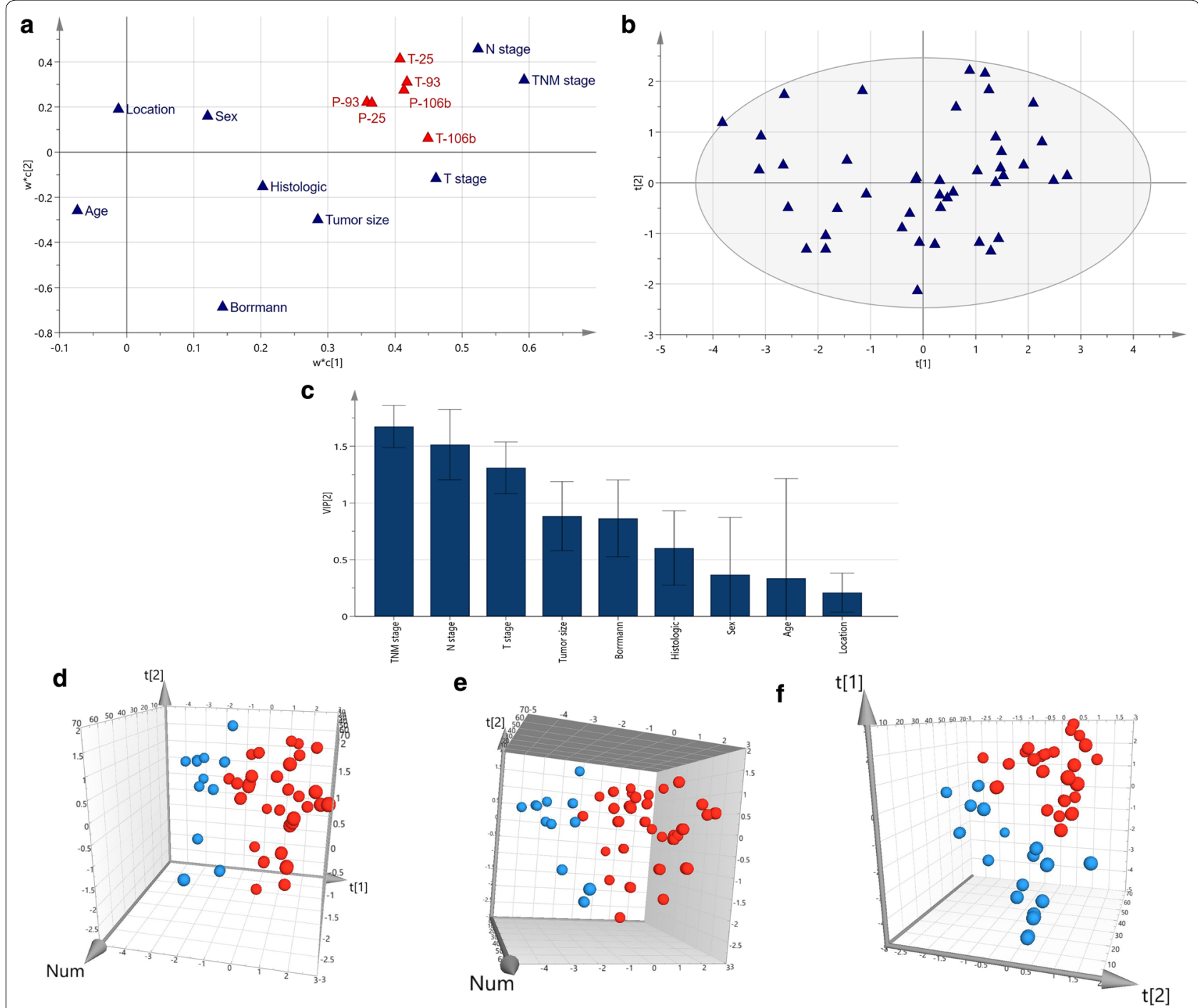

Fig. 3 PLS-DA analysis for clinicopathological features and miRNA 106b 25 in gastric cancer. a, b loading plot and score scatter in PLS-DA analysis. c VIP value of clinicopathological features for miRNA 106b 25 expression. d-f 3 D score plot according to T stage, N stage, TNM stage in PLS-DA, Blue: $\mathrm{T} 1+\mathrm{T} 2$, N0, TNM I+ II stage, respectively; Red: $\mathrm{T3}+\mathrm{T} 4, \mathrm{~N} 1-\mathrm{N} 3$, III + IV stage, respectively

93 and miRNA 25 were $2.516 \pm 0.971,2.885 \pm 0.785$, $2.275 \pm 0.867$.

Figure $1 \mathrm{~g}-\mathrm{i}$ showed the correlation analysis of plasma and tumor miRNA106b 25, the plasma miRNA 106b, miRNA 93 and miRNA 25 were positive correlated to tumor expression, respectively $\left(r^{2}=0.571, P<0.01\right.$; $\left.r^{2}=0.668, P<0.01 ; r^{2}=0.691, P<0.01\right)$.

\section{The multivariate analysis of the correlation} between miRNA106b 25 and clinicopathological features Clinicopathological features and miRNA 106b 25 expressions were set as variable $\mathrm{X}$ to establish the matrix for PCA analysis. As shown in Fig. 2a, b of loading plot and score scatter, Principal component 1 (PC1) and PC2 explained $54.1 \%$ and $44.2 \%$ variation, the total of $99.3 \%$ variation were explained by these two-PCs. Loading plot shows how the X-variables vary in relation to each other, variables near each other are positively correlated, variables symmetric about the origin to each other are negatively correlated, the variables situated at 90 degrees from each other are almost uncorrelated in these 2 components. Thus, the plasma and tumor miRNA 106b 25 expression, $\mathrm{T}$ stage, $\mathrm{N}$ stage, TNM stage were correlated each other.

Clinicopathological features were set as variable $\mathrm{X}$ to establish the matrix for PLS-DA analysis. The explain rate of first two PCs, $\mathrm{t} 1$ and $\mathrm{t} 2$ was $43.4 \%$ and $54.4 \%$, respectively. In PLS-DA analysis, X-variables with 
Table 2 Loading weights of all variables for the first and second components in PCA and PLS-DA analysis

\begin{tabular}{|c|c|c|c|c|}
\hline \multirow[t]{2}{*}{ Variables } & \multicolumn{2}{|l|}{ PCA } & \multicolumn{2}{|l|}{ PLS-DA } \\
\hline & M1.p (1) & M1.p (2) & $M 1 . w^{*} c(1)$ & $M 1 . w^{*} c(2)$ \\
\hline $\begin{array}{l}\text { Plasma miRNA } \\
106 \mathrm{~b}\end{array}$ & 0.336298 & 0.181996 & 0.413691 & 0.274102 \\
\hline $\begin{array}{l}\text { Plasma miRNA } \\
93\end{array}$ & 2204 & 0.186027 & 99 & 0.222264 \\
\hline $\begin{array}{l}\text { Plasma miRNA } \\
25\end{array}$ & 0.300041 & 0.316393 & 0.364789 & 0.215167 \\
\hline $\begin{array}{l}\text { Tumor miRNA } \\
\text { 106b }\end{array}$ & 0.338569 & -0.0933063 & 1 & 0.0596236 \\
\hline $\begin{array}{l}\text { Tumor miRNA } \\
93\end{array}$ & 0.326162 & 0.0910954 & 0.417487 & 0.308985 \\
\hline $\begin{array}{l}\text { Tumor miRNA } \\
25\end{array}$ & 0.324518 & 0.211675 & 0.407781 & 0.412313 \\
\hline Age & -0.0350196 & -0.170789 & -0.073876 & -0.260368 \\
\hline Sex & 0.0664001 & 0.040216 & 0.120416 & 0.160827 \\
\hline Location & -0.0172643 & 0.252373 & -0.0127198 & 0.189534 \\
\hline Bormann type & 0.132391 & -0.593899 & 0.142949 & -0.68586 \\
\hline Tumor size & 0.201582 & -0.114009 & 0.284582 & -0.299471 \\
\hline $\begin{array}{l}\text { Histological } \\
\text { type }\end{array}$ & 0.137613 & -0.367822 & 0.202056 & -0.151812 \\
\hline Tstage & 0.2992 & -0.32468 & 0.460746 & -0.116775 \\
\hline N stage & 0.29889 & 0.189293 & 0.523468 & 0.458886 \\
\hline TNM stage & 0.351118 & -0.162562 & 0.592729 & 0.320023 \\
\hline
\end{tabular}

large w*'s (positive or negative) are highly correlated with miRNA 106b 25 expression (Y). These variables with large $\mathrm{w}^{* \prime} \mathrm{s}$ are situated far away from the origin (on the positive or negative side) on the plot (Fig. 3a, b). Thus, T stage, N stage, TNM stage were correlated with plasma and tumor miRNA 106b 25 expression. We also identified that $\mathrm{T}$ stage, $\mathrm{N}$ stage, TNM stage were important factors to plasma and tumor miRNA 106b 25 expression via VIP(VIP value $=1.67482$, VIP value $=1.31006$, VIP value $=1.51526$, Fig. $3 \mathrm{c}$ ).

Both PCA and PLS-DA score plot (Figs. 2c-e, 3d-f) showed that all point can be disguised by $\mathrm{T}$ stage, $\mathrm{N}$ stage, TNM stage. T3-T4 stage, N1-N3 stage, III-IV stage distributed on the right, while T1-T2 stage, N0 stage, I-II stage distributed on the left according to their first and second PCs loading weight. However, such PCs are mainly correlated to the TNM stage, tumor and plasma miRNA 106b, tumor miRNA 93, tumor miRNA 25 (loading weights $>0.3$, first component), $\mathrm{T}$ stage and plasma miRNA25 (loading weights $>0.3$, second component) in PCA analysis. In PLS-DA analysis, first component is mainly correlated to the $\mathrm{N}$ stage, TNM stage, T stage, tumor miRNA106b, miRNA 25 and miRNA93 (loading weights $>0.4$ ), second component are mainly correlated to $\mathrm{N}$ stage, tumor miRNA25, tumor miRNA93 (loading weights $>0.3$, shown in Table 2). This result confirms the
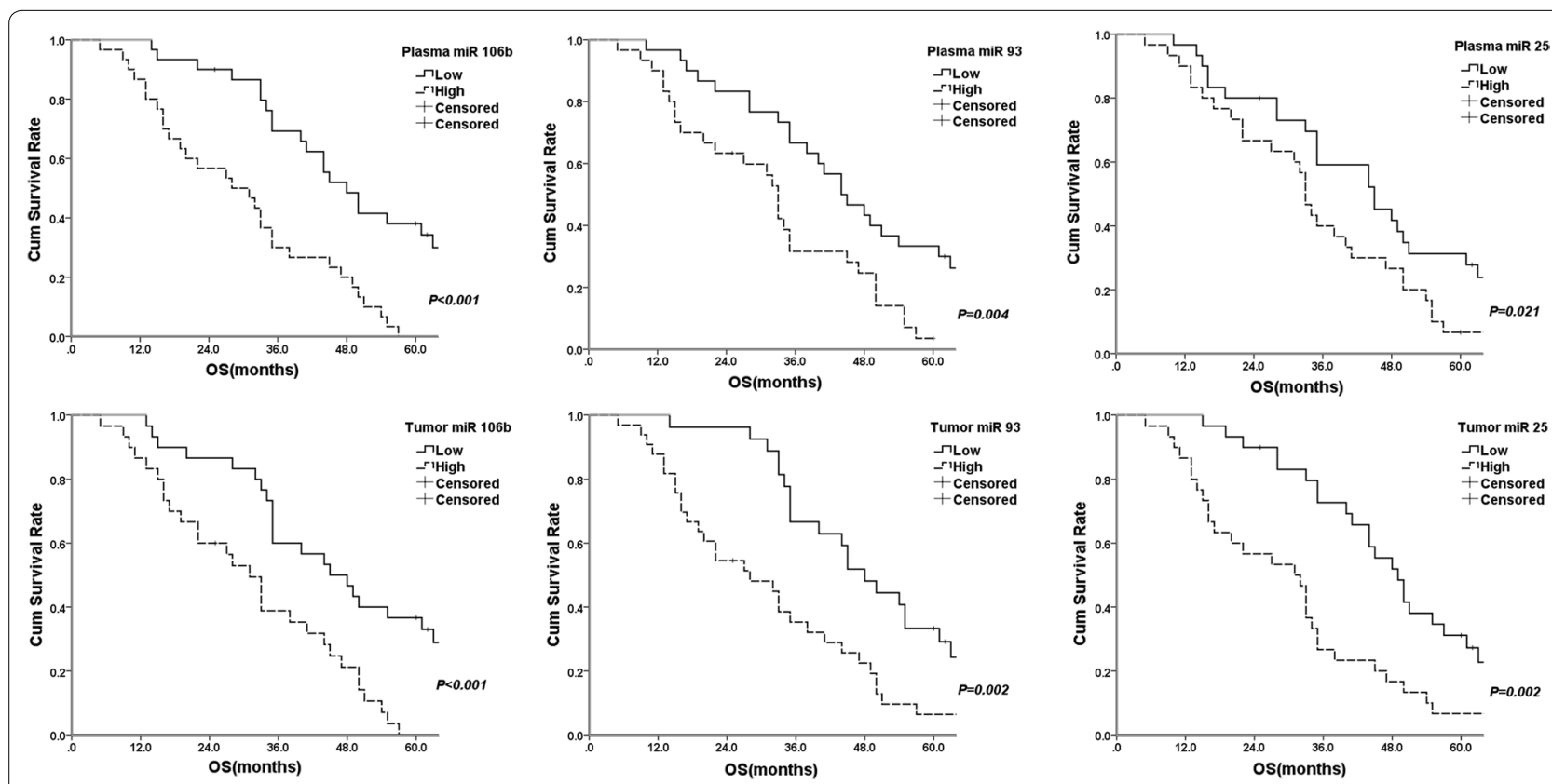

Fig. 4 The survival curves according to plasma and tumor miRNA106b 25 of gastric cancer patients 
Table 3 1,3 and 5 year-survival rate of gastric cancer patients according to clinicopathological features and miRNA 106b 25

\begin{tabular}{|c|c|c|c|c|c|c|}
\hline \multirow[t]{2}{*}{ Clinicopathological features } & \multirow[t]{2}{*}{ Total } & \multicolumn{5}{|l|}{ os } \\
\hline & & $1-Y S R$ & 3-YSR & 5-YSR & $\mathrm{x}^{2}$ & $P$ \\
\hline \multicolumn{7}{|l|}{ Age } \\
\hline$<55$ & 20 & 95.0 & 42.9 & 0.00 & \multirow[t]{2}{*}{2.951} & \multirow[t]{2}{*}{0.086} \\
\hline$\geq 55$ & 40 & 92.5 & 52.5 & 27.5 & & \\
\hline \multicolumn{7}{|l|}{ Sex } \\
\hline Male & 53 & 94.3 & 50.3 & 21.3 & \multirow[t]{2}{*}{1.945} & \multirow[t]{2}{*}{0.163} \\
\hline Female & 7 & 85.7 & 42.9 & 0.00 & & \\
\hline \multicolumn{7}{|l|}{ Tumor location } \\
\hline Proximal & 16 & 93.8 & 56.3 & 18.8 & \multirow[t]{3}{*}{3.271} & \multirow[t]{3}{*}{0.105} \\
\hline Middle & 12 & 91.7 & 33.3 & 0.00 & & \\
\hline Distal & 32 & 90.6 & 52.3 & 7.9 & & \\
\hline \multicolumn{7}{|l|}{ Tumor size $(\mathrm{cm})$} \\
\hline$<5$ & 26 & 96.2 & 73.1 & 38.5 & \multirow[t]{2}{*}{18.001} & \multirow[t]{2}{*}{0.000} \\
\hline$\geq 5$ & 34 & 91.2 & 31.0 & 3.1 & & \\
\hline \multicolumn{7}{|l|}{ Bormann type } \\
\hline $1+\|$ & 19 & 95.2 & 52.4 & 23.8 & \multirow[t]{2}{*}{0.772} & \multirow[t]{2}{*}{0.380} \\
\hline$I I I+I V$ & 41 & 92.3 & 47.9 & 0.160 & & \\
\hline \multicolumn{7}{|l|}{ Tstage } \\
\hline $\mathrm{T} 1, \mathrm{~T} 2$ & 16 & 93.8 & 75.0 & 43.8 & \multirow[t]{2}{*}{5.914} & \multirow[t]{2}{*}{0.015} \\
\hline $\mathrm{T} 3, \mathrm{~T} 4$ & 44 & 90.9 & 40.1 & 9.4 & & \\
\hline \multicolumn{7}{|l|}{ N stage } \\
\hline NO & 19 & 94.7 & 89.5 & 47.4 & 19.460 & 0.000 \\
\hline $\mathrm{N} 1-\mathrm{N} 3$ & 41 & 90.2 & 30.5 & 5.1 & & \\
\hline TNM stage & & & & & & \\
\hline I, II & 24 & 95.8 & 83.3 & 41.7 & 24.450 & 0.000 \\
\hline III, IV & 36 & 88.9 & 32.2 & 2.9 & & \\
\hline Histological grade (-differentiat & & & & & & \\
\hline Well & 17 & 94.1 & 52.9 & 23.5 & 0.445 & 0.505 \\
\hline Poor & 43 & 90.7 & 48.1 & 16.8 & & \\
\hline Plasma miRNA $106 b^{a}$ & & & & & & \\
\hline Low & 30 & 96.7 & 69.2 & 38.1 & 17.219 & 0.000 \\
\hline High & 30 & 86.7 & 30.0 & 0.00 & & \\
\hline Plasma miRNA $93^{\mathrm{a}}$ & & & & & & \\
\hline Low & 30 & 96.7 & 66.7 & 33.3 & 8.401 & 0.004 \\
\hline High & 30 & 90.0 & 31.7 & 3.5 & & \\
\hline Plasma miRNA $25^{\mathrm{a}}$ & & & & & & \\
\hline Low & 30 & 96.7 & 59.1 & 31.3 & 5.358 & 0.029 \\
\hline High & 30 & 90.0 & 40.0 & 6.7 & & \\
\hline Tumor miRNA $106 b^{a}$ & & & & & & \\
\hline Low & 30 & 96.3 & 66.7 & 33.3 & 12.533 & 0.000 \\
\hline High & 30 & 87.9 & 35.3 & 6.4 & & \\
\hline Tumor miRNA $93^{\mathrm{a}}$ & & & & & & \\
\hline Low & 30 & 96.3 & 66.7 & 33.7 & 9.318 & 0.002 \\
\hline High & 30 & 87.9 & 35.3 & 6.4 & & \\
\hline Tumor miRNA $25^{\mathrm{a}}$ & & & & & & \\
\hline Low & 30 & 96.7 & 72.7 & 31.2 & 10.047 & 0.002 \\
\hline High & 30 & 86.7 & 26.7 & 6.7 & & \\
\hline
\end{tabular}

YSR year survival rate

${ }^{a}$ Median was set as cut-off value; low was $\leq$ median; high was $>$ median 
Table 4 Multivariate COX regression for prognostic features of gastric cancer patients

\begin{tabular}{|c|c|c|c|c|c|c|}
\hline Features & $\beta$ & SE & Wald & df & $\mathbf{P}$ & HR $(95 \% \mathrm{Cl})$ \\
\hline \multicolumn{7}{|l|}{ T stage } \\
\hline $\mathrm{T} 1, \mathrm{~T} 2$ & -0.916 & 0.341 & 7.229 & 1 & 0.007 & $0.400(0.205-0.780)$ \\
\hline \multicolumn{7}{|l|}{$\mathrm{T} 3, \mathrm{~T} 4$} \\
\hline \multicolumn{7}{|l|}{ N stage } \\
\hline NO & 0.612 & 0.714 & 0.734 & 1 & 0.392 & $1.844(0.455-7.470)$ \\
\hline \multicolumn{7}{|l|}{ N1-N3 } \\
\hline \multicolumn{7}{|l|}{ TNM stage } \\
\hline I, II & 0.703 & 0.446 & 2.485 & 1 & 0.115 & $2.019(0.843-4.839)$ \\
\hline \multicolumn{7}{|l|}{ III, IV } \\
\hline \multicolumn{7}{|l|}{ Tumor size } \\
\hline$<5$ & 0.832 & 0.494 & 2.839 & 1 & 0.092 & $2.297(0.873-6.042)$ \\
\hline \multicolumn{7}{|l|}{$>5$} \\
\hline \multicolumn{7}{|c|}{ Plasma miR 106b } \\
\hline Low & -0.990 & 0.489 & 4.099 & 1 & 0.043 & $0.371(0.142-0.969)$ \\
\hline \multicolumn{7}{|l|}{ High } \\
\hline \multicolumn{7}{|c|}{ Plasma miR 93} \\
\hline Low & -0.125 & 0.403 & 0.096 & 1 & 0.757 & $0.882(0.400-1.946)$ \\
\hline \multicolumn{7}{|l|}{ High } \\
\hline \multicolumn{7}{|c|}{ Plasma miR 25} \\
\hline Low & 0.555 & 0.407 & 1.861 & 1 & 0.172 & $1.742(0.785-3.866)$ \\
\hline \multicolumn{7}{|l|}{ High } \\
\hline \multicolumn{7}{|c|}{ Tumor miR 106b } \\
\hline Low & 0.220 & 0.377 & 0.340 & 1 & 0.560 & $1.246(0.595-2.612)$ \\
\hline \multicolumn{7}{|l|}{ High } \\
\hline \multicolumn{7}{|c|}{ Tumor miR 93} \\
\hline Low & -1.220 & 0.403 & 9.162 & 1 & 0.002 & $0.295(0.134-0.650)$ \\
\hline \multicolumn{7}{|l|}{ High } \\
\hline \multicolumn{7}{|c|}{ Tumor miR 25} \\
\hline Low & -0.029 & 0.477 & 0.004 & 1 & 0.951 & $0.971(0.381-2.473)$ \\
\hline High & & & & & & \\
\hline
\end{tabular}

To get adjusted hazard ratios, COX regression was applied for adjusting significant covariate in Kaplan-Meier prognostic analysis

$\beta$ regression coefficient, $S E$ standard error, Wald wald Chi square; $d f$ degree of freedom, $H R$ hazard ratio

importance of the miRNAs 106b 25 expression carried with the progressed stage of gastric cancer.

\section{Prognostic analysis}

In the survival analysis, tumor size $(P<0.01), \mathrm{T}$ stage $(P=0.015), \mathrm{N}$ stage $(P<0.01)$, TNM stage $(P<0.01)$, plasma miRNA 106b $(P<0.001)$, plasma miRNA 93 $(P=0.004)$, plasma miRNA25 $(P=0.029)$, tumor miRNA 106b $(P<0.001)$, tumor miRNA $93(P=0.002)$, tumor miRNA25 $(P=0.002)$, was significantly correlated with OS (Fig. 4). The survival rates based on clinicopathological features and miRNA 106b 25 were list in Table 3. In Table 4, we used COX regression to get adjusted hazard ratios for prognosis. T stage, plasma miRNA 106b and tumor miRNA 93 are significant risk factors for overall survival [HR: 0.400 (0.205-0.780); $P=0.007$; HR: 0.371 (0.142-0.969), $P=0.043 ; 0.295$ (0.134-0.650), $P=0.002]$.

\section{Discussion}

Increasing studies has showed that miRNA 106b 25 cluster plays oncogenic roles in malignant disease. miRNA 106b 25 has been reported to be up-regulated in several cancers, including esophageal squamous cell carcinoma [21], breast cancer [19], hepatocellular carcinoma [20] et al. The regulation targets of miRNA $106 \mathrm{~b} 25$ involving E2F1 and TGF- $\beta$, RB, TP53 [23], PTEN [24] et al. All these targets play crucial role as an intrinsic factor of gastric carcinogenesis. In our previous studies, we had demonstrated expression of miRNA 106b, miRNA 93 and miRNA 25 were significantly higher in gastric cancer 
cell lines [26], tumor tissues and plasma form gastric cancer patients [27]. In this study, we analyzed the significance of miRNA106b 25 on clinicopathological features and prognosis of gastric cancer patients via multivariate analysis.

Multivariate analysis is able to perform trade studies across multiple dimensions whereas taking into account the effects of all variables on the responses of interest, as well as clinical and pathological features and miRNAs expression in this study, and in purpose of extract the important variable for the classification. PCA is a technique of data dimensionality reduction [29]. It contains a series of mathematical procedure which transforms a range of correlated variables into a (smaller) number of uncorrelated variables defined PCs, thus $\mathrm{PCs}$ is integrated to extract the main information of data sets. Scattered plots of PCA can show the biological alterations behind the data sets appropriately. The high coincidence of PCs and similarities in PC element could be achieved indifferent samples within similar pathological or pathophysiological status, so as to, these coincident constituents is in similar location in PCA scattered plots. In this study, scattered plots showed that the plasma and tumor miRNA 106b 25 expression, $\mathrm{T}$ stage, $\mathrm{N}$ stage, TNM stage were in similar location and correlated with each other.

PCA is a foundation for the algorithm of PLS-DA. PLS-DA is a partial least squares regression of binary variables, which can analyze the categories of a categorical variable $(\mathrm{X})$ for predictor variables $(\mathrm{Y})$. It is an coordination among the usual discriminant analysis and a discriminant analysis based on the significant PCs for the Y variables [12]. We used VIP and loading plots of PLS-DA analysis to identify the important X variables for the miRNA 106b 25s, it was showed that $\mathrm{T}$ stage, $\mathrm{N}$ stage, TNM stage were important factors to plasma and tumor miRNA 106b 25 expression.

In prognostic analyze, we used Kaplan-Meier analysis to prognostic univariate analysis. The Cox regression (or proportional hazards regression) is a statistical approach for investigating the effect of several variables upon the time a specified event takes to happen. In the context of an outcome such as death or disease progression this is known as Cox regression for survival analysis. The unique effect of a unit increase in a covariate is multiplicative with respect to the hazard rate. In this study, the cox regression showed that $\mathrm{T}$ stage, plasma miRNA 106b and tumor miRNA 93 significant risk factors for overall survival, the HR was $0.400,0.371,0.295$, respectively.

\section{Conclusion}

miRNA 106b 25 expression in plasma and tumor correlated with $\mathrm{T}$ stage, $\mathrm{N}$ stage, TNM stage. miRNA 106b 25s expression increasing was important characters carried in the progressing stage of gastric cancer. T stage, plasma miRNA 106b and tumor miRNA 93 significant risk factors for overall survival.

\section{Additional file}

Additional file 1: Table S1. The expression of miRNA 106b 25 in TCGA database.

\section{Acknowledgements}

None.

\section{Authors' contributions}

$\mathrm{FL}, \mathrm{JH}$ and $\mathrm{J}$ analyzed and interpreted the patient data. $\mathrm{FL}$ and $\mathrm{JH}$ performed the RT-PCR of the cancer tissues, and FL was a major contributor in writing the manuscript. WX and ZY was contributed to RT-PCR and revised the manuscript. All authors read and approved the final manuscript.

\section{Funding statement}

None.

\section{Availability of data and materials}

The datasets used during the current study are available from the corresponding author on reasonable request.

\section{Ethics approval and consent to participate}

This research project was approved by the Ethics Committee of Tianjin Cancer Institute and Hospital. Written consents were obtained from each patient.

\section{Consent for publication}

Written consents were obtained from each patient to publishing their pathological images as represent Figures.

\section{Competing interests}

The authors declare that they have no competing interests.

Received: 9 April 2019 Accepted: 22 July 2019

Published online: 29 July 2019

\section{References}

1. Brett JO, Renault VM, Rafalski VA, Webb AE, Brunet A. The microRNA cluster miR-106b 25 regulates adult neural stem/progenitor cell proliferation and neuronal differentiation. Aging. 2011;3(2):108-24. https://doi. org/10.18632/aging.100285.

2. Chen XZ, Zhang WK, Yang K, Wang LL, Liu J, Wang L, Hu JK, Zhang B, Chen ZX, Chen JP, Zhou ZG, Mo XM. Correlation between serum CA724 and gastric cancer: multiple analyses based on Chinese population. Mol Biol Rep. 2012;39(9):9031-9. https://doi.org/10.1007/s11033-012-1774-x.

3. Fang L, Deng Z, Shatseva T, Yang J, Peng C, Du WW, Yee AJ, Ang LC, He C, Shan SW, Yang BB. MicroRNA miR-93 promotes tumor growth and angiogenesis by targeting integrin-beta8. Oncogene. 2011;30(7):806-21. https://doi.org/10.1038/onc.2010.465.

4. Guarnieri AL, Towers CG, Drasin DJ, Oliphant M, Andrysik Z, Hotz TJ, Vartuli RL, Linklater ES, Pandey A, Khanal S, Espinosa JM, Ford HL. The miR106b-25 cluster mediates breast tumor initiation through activation of NOTCH1 via direct repression of NEDD4L. Oncogene. 2018;37(28):3879_ 93. https://doi.org/10.1038/s41388-018-0239-7.

5. Guo J, Miao Y, Xiao B, Huan R, Jiang Z, Meng D, Wang Y. Differential expression of microRNA species in human gastric cancer versus 
non-tumorous tissues. J Gastroenterol Hepatol. 2009;24(4):652-7. https:// doi.org/10.1111/j.1440-1746.2008.05666.x.

6. Haldar S, Roy A, Banerjee S. Differential regulation of MCM7 and its intronic miRNA cluster miR-106b-25 during megakaryopoiesis induced polyploidy. RNA Biol. 2014;11(9):1137-47. https://doi.org/10.4161/ rna.36136.

7. Hudson RS, Yi M, Esposito D, Glynn SA, Starks AM, Yang Y, Schetter AJ, Watkins SK, Hurwitz AA, Dorsey TH, Stephens RM, Croce CM, Ambs S. MicroRNA-106b-25 cluster expression is associated with early disease recurrence and targets caspase-7 and focal adhesion in human prostate cancer. Oncogene. 2013;32(35):4139-47. https://doi.org/10.1038/ onc.2012.424.

8. Kan T, Sato F, Ito T, Matsumura N, David S, Cheng Y, Agarwal R, Paun BC, Jin Z, Olaru AV, Selaru FM, Hamilton JP, Yang J, Abraham JM, Mori Y, Meltzer SJ. The miR-106b-25 polycistron, activated by genomic amplification, functions as an oncogene by suppressing p21 and Bim. Gastroenterology. 2009;136(5):1689-700.

9. Khuu C, Utheim TP, Sehic A. The three paralogous microRNA clusters in development and disease, miR-17-92, miR-106a-363, and miR-106b-25. Scientifica. 2016;2016:1379643. https://doi.org/10.1155/2016/1379643.

10. Kim YK, Yu J, Han TS, Park SY, Namkoong B, Kim DH, Hur K, Yoo MW, Lee $H J$, Yang HK, Kim VN. Functional links between clustered microRNAs: suppression of cell-cycle inhibitors by microRNA clusters in gastric cancer. Nucleic Acids Res. 2009;37(5):1672-81. https://doi.org/10.1093/nar/gkp00 2.

11. Li F, Guo Y, Liu J, Zhang R. The significance of elevated plasma expression of microRNA 106b 25 clusters in gastric cancer. PLoS ONE. 2017;12(5):e178427. https://doi.org/10.1371/journal.pone.0178427.

12. Li X, Gill R, Cooper NG, Yoo JK, Datta S. Modeling microRNA-mRNA interactions using PLS regression in human colon cancer. BMC Med Genomics. 2011:4:44. https://doi.org/10.1186/1755-8794-4-44.

13. Mirzaei H, Khataminfar S, Mohammadparast S, Sales SS, Maftouh M, Mohammadi M, Simonian M, Parizadeh SM, Hassanian SM, Avan A. Circulating microRNAs as potential diagnostic biomarkers and therapeutic targets in gastric cancer: current status and future perspectives. Curr Med Chem. 2016;23(36):4135-50.

14. Petrocca F, Vecchione A, Croce CM. Emerging role of miR-106b-25/miR17-92 clusters in the control of transforming growth factor beta signaling. Cancer Res. 2008;68(20):8191-4. https://doi.org/10.1158/0008-5472. can-08-1768.

15. Poliseno L, Salmena L, Riccardi L, Fornari A, Song MS, Hobbs RM, Sportoletti P, Varmeh S, Egia A, Fedele G, Rameh L, Loda M, Pandolfi PP. Identification of the miR-106b 25 microRNA cluster as a proto-oncogenic PTEN-targeting intron that cooperates with its host gene MCM7 in transformation. Sci Signal. 2010;3(117):a29. https://doi.org/10.1126/scisi gnal.2000594.

16. Qi F, Huang M, Pan Y, Liu Y, Liu J, Wen J, Xie K, Shen H, Ma H, Miao Y, Hu Z. A genetic variant in the promoter region of miR-106b-25 cluster predict clinical outcome of HBV-related hepatocellular carcinoma in Chinese. PLOS ONE. 2014;9(1):e85394. https://doi.org/10.1371/journal.pone.00853 94.

17. Savita U, Karunagaran D. MicroRNA-106b-25 cluster targets beta-TRCP2, increases the expression of Snail and enhances cell migration and invasion in H1299 (non small cell lung cancer) cells. Biochem Biophys Res Commun. 2013;434(4):841-7. https://doi.org/10.1016/j.bbrc.2013.04.025.

18. Siegel RL, Miller KD. Jemal A (2018) Cancer statistics. CA Cancer J Clin. 2018;68(1):7-30. https://doi.org/10.3322/caac.21442.
19. Smith AL, Iwanaga R, Drasin DJ, Micalizzi DS, Vartuli RL, Tan AC, Ford HL. The miR-106b-25 cluster targets Smad7, activates TGF-beta signaling, and induces EMT and tumor initiating cell characteristics downstream of Six1 in human breast cancer. Oncogene. 2012;31(50):5162-71. https://doi. org/10.1038/onc.2012.11.

20. Tan W, Li Y, Lim SG, Tan TM. miR-106b-25/miR-17-92 clusters: polycistrons with oncogenic roles in hepatocellular carcinoma. World J Gastroenterol. 2014;20(20):5962-72. https://doi.org/10.3748/wjg.v20.i20.5962.

21. Wang M, Yang YO, Jin Q, Shang L, Zhang J. Function of miR-25 in the invasion and metastasis of esophageal squamous carcinoma cells and bioinformatical analysis of the miR-106b-25 cluster. Exp Ther Med. 2018;15(1):440-6. https://doi.org/10.3892/etm.2017.5358.

22. Xu X, Liu Z, Wang J, Ling Q, Xie H, Guo H, Wei X, Zhou L, Zheng S. miRNA profiles in livers with different mass deficits after partial hepatectomy and miR-106b 25 cluster accelerating hepatocyte proliferation in rats. Sci Rep. 2016;6:31267. https://doi.org/10.1038/srep31267.

23. Yeung ML, Yasunaga J, Bennasser Y, Dusetti N, Harris D, Ahmad N, Matsuoka M, Jeang KT. Roles for microRNAs, miR-93 and miR-130b, and tumor protein 53-induced nuclear protein 1 tumor suppressor in cell growth dysregulation by human T-cell lymphotropic virus 1. Cancer Res. 2008;68(21):8976-85. https://doi.org/10.1158/0008-5472.can-08-0769.

24. Zhang H, Yan X. Cantharidin modulates the E2F1/MCM7-miR-106b-93/ p21-PTEN signaling axis in MCF-7 breast cancer cells. Oncol Lett. 2015;10(5):2849-55. https://doi.org/10.3892/ol.2015.3681.

25. Zhang R, Guo Y, Ma Z, Ma G, Xue Q, Li F, Liu L. Long non-coding RNA PTENP1 functions as a ceRNA to modulate PTEN level by decoying miR106b and miR-93 in gastric cancer. Oncotarget. 2017;8(16):26079-89. https://doi.org/10.18632/oncotarget.15317.

26. Zhang R, Li F, Wang W, Wang X, Li S, Liu J. The effect of antisense inhibitor of miRNA 106b approximately 25 on the proliferation, invasion, migration, and apoptosis of gastric cancer cell. Tumour Biol. 2016;37(8):10507-15. https://doi.org/10.1007/s13277-016-4937-X.

27. Zhang R, Wang W, Li F, Zhang H, Liu J. MicroRNA-106b 25 expressions in tumor tissues and plasma of patients with gastric cancers. Med Oncol. 2014;31(10):243. https://doi.org/10.1007/s12032-014-0243-x.

28. Zhao B, Zhang J, Zhang J, Luo R, Wang Z, Xu H, Huang B. Assessment of the 8th edition of TNM staging system for gastric cancer: the results from the SEER and a single-institution database. Future Oncol. 2018. https:// doi.org/10.2217/fon-2018-0299.

29. Zheng WS, Lai J, Yuen PC. Penalized preimage learning in kernel principal component analysis. IEEE Trans Neural Netw. 2010;21 (4):551-70. https:// doi.org/10.1109/tnn.2009.2039647.

30. Zhu S, Li Y, Xiao W, Yang Y. High expression of GM is associated with poor prognosis of gastric cancer patients. Onco Targets Ther. 2019;12:4379-89. https://doi.org/10.2147/OTT.S203345.

\section{Publisher's Note}

Springer Nature remains neutral with regard to jurisdictional claims in published maps and institutional affiliations.

Ready to submit your research? Choose BMC and benefit from:

- fast, convenient online submission

- thorough peer review by experienced researchers in your field

- rapid publication on acceptance

- support for research data, including large and complex data types

- gold Open Access which fosters wider collaboration and increased citations

- maximum visibility for your research: over 100M website views per year

At BMC, research is always in progress.

Learn more biomedcentral.com/submissions 